\title{
Calorimetrical observations on the disengagement of heat and light in electrical discharges
}

\section{G. Staub}

To cite this article: G. Staub (1890) Calorimetrical observations on the disengagement of heat and light in electrical discharges, Philosophical Magazine Series 5, 30:184, 283-284, DOI: 10.1080/14786449008620024

To link to this article: http://dx.doi.org/10.1080/14786449008620024

曲 Published online: 08 May 2009.

Submit your article to this journal $[\pi$

Џ Article views: 2

Q View related articles $\widetilde{ }$ 
height of the liquid in the tubes is changed during the equalization into vis viva of the liquid. This may again be transformed into energy of the original kind, so that the fresh difference in height has the opposite position to the former. In the convertibility of the two energies into each other is found the reason of the ribratory motion which would otherwise be conceived to be due to inertia. If, owing to friction, part of the energy is transformed into heat, which is not convertible, the amplitudes of the vibrations are continually slower. The motion is as if the liquid had not complete inertia.

To the difference of potentials between the plates of a charged condenser an electrical energy corresponds. If the plates are connected by a wire, part of this energy is converted into heat, owing to resistance; the rest is again changed into another energy, which, as the fact of the oscillating discharge shows, may again be transformed into an electrostatic one, in such a manner that a difference of potential is established in the condenser opposite to the original one. The question is, of what value is this energy? In the special case in which the discharging wire is passed spirally round an iron core, the nature of the greatest part of this energy is known. It is the magnetic energy which is accumulated in the nagnetized iron during the equalization of the discharge, and which after the equalization is complete still maintains a current in the same direction, and charges the condenser afresh, but in the opposite direction. It is simplest, even in case there is no magnetic core, to conceive this energy as a magnetic one which has its seat in the magnetization of the medium in which the discharge takes place. This assumption is sufficient also for establishing the laws of electrodynamic induction.-Wiener Sitzungsberichte, June 12, 1890 .

CALORIMETRICAL OBSERVATIONS ON THE DISENGAGEMENT OF HEAT AND LIGHT IN ELECTRICAL DISCHARGES. BY G. STAUB.

The author determines the ratio $\mathrm{N}$ of the total energy $\mathrm{E}$ emitted by a gas to that which is perceived as light $L$. With this view he introduces a Geissler's tube into an ice-calorimeter from the bottom of which the mercury is removed. The ice and water transmit all the rays of ligbt and only absorb those of heat; he then blackens the Geissler tube, and thus retains the visible rays also in the icecalorimeter. If the quantity of heat in the first case is $Q$ and in the second $\mathrm{E}, \mathrm{I}=\mathrm{E}-\mathrm{Q}$.

The width of the Geissler tube was altered as well as the pressure in it, and condensers and also breaks were interposed in the circuit. The results of the experiment were as follows.

With the help of electrical discharges in Geissler tubes, light of considerably greater useful effect may be obtained than in the glowlamp. The maximum for one of Blattner's was 10 per cent., and for a Geissler tube with condensers $32 \cdot 8$ per cent. The useful 
effect increases with the density and quantity of electricity which passes through the tube. It decreases as the pressure and diameter of the capillary tube increases. If the Geissler tube is filled with hydrogen, the optical effect is less than in air, other things being equal.

These results agree with the experiments on glow-lamps and flames, in so far that the higher the temperature the higher in general is the useful effect.-Beiblätter der Physil, rol. xiv. p. 538.

\section{OBSERVATIONS ON ATMOSPHERIO ELECTRICITY IN THE TROPICS. BY PROF. F. EXNER.}

The present paper forms the conclusion of a former one which appeared under the same title (Phil. Mag. vol. xxix. p. 520), and gives a complete discussion of the measurements contained in the latter. The connexion between fall of potential and vapourpressure, which the author found to exist in our regions, is also fully confirmed for the tropics, so that we may now regard the electrical constants of the earth as determined with great certainty. The quantity of electricity which is found in a column of a square centimetre base above the earth's surface is, including the charge of the latter, -0.0038 absolute electrostatic units. The total charge $Q$ of the earth is, $Q=-2 \times 10^{16}$ in the same units, and its potential $V$ referred to a point in space is $-9 \times 10^{9}$ volt. A further fact now fully established is that the sign of the normal fall of potential in the tropics is the same as with us, that is positive. Only few observations could be made as to the change of fall of potential with height, yet this showed distinctly an increase as required by theory.

The daily period of atmospheric electricity is decidedly less pronounced in the tropics than with us, which is probably connected with the extraordinary constancy of the weather. On most days maxima could not be observed.-Wiener Berichte, July 10, 1890.

\section{INVESTIGATION OF ELECTRICAL VIBRATIONS WITH THERMO- ELEMENTS. BY DR. IGNATIUS KLEMENCIC.}

The author investigated Hertz's vibrations by the help of a thermoelement soldered between the ends of the secondary inductor. By using two such inductors, one of which served as standard while the other was moved about in the space affected, it was possible to measure the distribution of energy in a ray proceeding from the primary mirror, and at right angles to it. The factor of condensation of a secondary mirror was furtber measured for two different pairs of primary conductors, and was found to be 7 for a pair made exactly according to Hertz's directions, and equal to $2 \cdot 7$ for a pair twice as long. The mirrors were exactly of the dimensions mentioned by Hertz.-Wiener Berichte, July 17, 1890. 